\title{
SISTEMAS DE TELECOMUNICAÇÕES: UMA ABORDAGEM NAS CIDADES PEQUENAS DO TERRITÓRIO DO SISAL NO ESTADO DA BAHIA.
}

\author{
Bruna Suellen Oliveira Mota ${ }^{1}$; Edinusia Moreira Carneiro Santos ${ }^{2}$ \\ 1. Bolsista FAPESB, Graduando em Licenciatura em Geografia, Universidade Estadual de Feira de Santana, e-mail: \\ brunasuellen.om@gmail.com \\ 2. Orientador, Departamento de Ciências Humanas e Filosofia, Universidade Estadual de Feira de Santana, e-mail: \\ nusiafs@hotmail.com
}

PALAVRAS-CHAVE: Telecomunicações; cidades pequenas; redes

\section{INTRODUÇÃO}

A presente pesquisa buscou compreender a dinâmica das Telecomunicações nas dezoito Cidades Pequenas do Território do Sisal: Araci, Barrocas, Biritinga, Candeal, Cansanção, Ichú, Itiúba, Lamarão, Monte Santo, Nordestina, Queimadas, Quijingue, Retirolândia, Santaluz, São Domingos, Teofilândia, Tucano e Valente.

A fim de analisar a influência dos fixos e fluxos (Santos, 2006) impulsionados pelos meios de telecomunicações na reorganização das pequenas cidades do Território do Sisal, foram analisados: telefonia móvel e fixa, emissoras de rádio, provedores de internet e portais de notícias, e aparelhos retransmissores de sinal de TV, visto que as telecomunicações são um meio técnico que se constitui de aparatos tecnológicos, os quais estão sujeitos à sucessivas mudanças e adequações, influenciando fortemente as dinâmicas espaciais desde suas materialidades às funções e intenções. Tal investigação, representa um estudo de grande relevância por se tratar de um sistema muito influente no atual período técnico-cientificoinformacional e pouco pesquisado em cidades pequenas. Dessa forma, trará dados importantes para conhecimento, tanto da população das cidades como da Geografia.

\section{PROCEDIMENTOS METODOLÓGICOS}

O trabalho se desenvolveu de modo processual, inicialmente houve o levantamento de bases que possibilitaram a produção do referencial teórico, sobre telecomunicações, cidades pequenas e redes. Posteriormente, foi feita a coleta de dados secundários através do site da Agência Nacional de Telecomunicações (ANATEL), Ministério das Comunicações, e Superintendência de Estudos Econômicos e Sociais da Bahia (SEI) e Instituto Brasileiro de Geografia e Estatística (IBGE), possibilitando a aquisição de informações referentes a utilização dos serviços por cidade. Prosseguindo foi realizada a confecção de mapa, gráficos e quadros, a partir dos dados colhidos na etapa anterior. Finalizando, foram analisados todos os dados obtidos e produzido o relatório final. Esse resumo apresenta uma síntese desses resultados.

\section{RESULTADOS E/OU DISCUSSÃO (ou Análise e discussão dos resultados)}

A partir da obtenção de dados acerca do acesso aos meios de Telecomunicações nas dezoito Cidades Pequenas do Território do Sisal, foi possível a construção de gráficos, quadros e mapa expondo Conceição do Coité e Serrinha apenas a nível comparativo.

O gráfico 01 demonstra a quantidade de acessos à Comunicação Multimídia nas 18 cidades pequenas do Território do Sisal, para os anos de 2011 à 2016 segundo estatísticas obtidas junto a ANATEL. Identifica-se de modo geral, uma variedade considerável de acessos ao longo dos 6 anos dentre aumentos e decréscimos, justificando-se pelo fato de em 8 cidades: Barrocas Biritinga, Candeal, Ichú, Quijingue e Retirolândia apresentarem um aumento evidente de acessos principalmente nos anos de 2013 e 2014 e posteriormente um decréscimo, enquanto em outras 4 cidades: Araci, Queimadas, São Domingos e Valente o aumento se dá nos anos de 2013 e 2015. Já para o ano de 2016, 5 cidades: Cansanção, Itiúba, Nordestina, 
Santaluz e Teofilândia apresentam rendimento superior aos demais anos. Vale ressaltar que os anos de 2011 e 2012, detém os menores valores respectivamente, com exceção à cidade de Araci no ano de 2012. Tucano é a cidade que possui maior quantidade de acesso anual entre todas as cidades pequenas no ano de 2014 com a maior média obtida de 1.864,5.

Conforme as análises, as Cidades Pequenas apresentam diferentes níveis de incorporação à comunicação eletrônica, inferindo-se que a atuação irregular do capital, que se materializa na dinâmica econômica no território que promove a organização do mesmo através da incorporação das tecnologias às práticas de mercado.

Gráfico 01:

Acesso do Serviço de Comunicação Multimídia

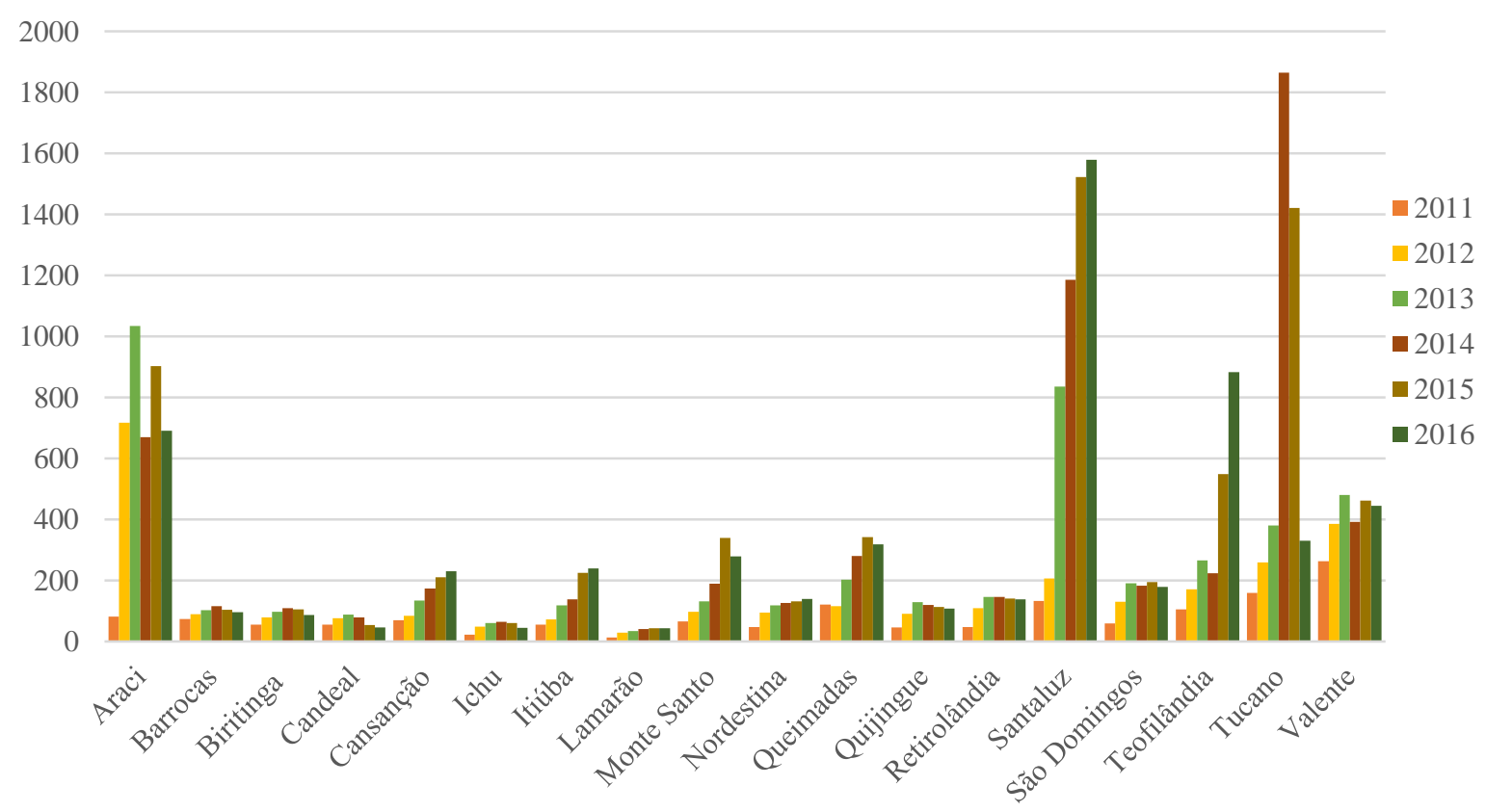

FONTE: Anatel, 2017.

ELABORAÇÃO: MOTA, B.S.O. 2017

Analisando os dados obtidos do acesso à TV por assinatura, houve uma estabilidade entre os anos de 2012 à 2016 não havendo variações significativas para a quantidade de acessos, com exceção de 5 cidades, sendo elas: Monte Santo, Quijingue, Santaluz, São Domingos e Tucano, as quais apresentam valores crescentes no decorrer dos anosanalisados, enquanto Ichú apresenta um contraste quando relacionado às demais cidades citadas, com valores decrescentes. Pode-se ressaltar que dentre as cidades analisadas, se destacam Tucano e Santaluz. Em oposição a pequena cidade Nordestina detém os menores valores de acesso, chegando a alcançar uma média anual de somente 9,5 acessos no ano de 2014.

Quanto a quantidade de Telefone de Uso Público (TUP) ativos nas 18 cidades pequenas do Território do Sisal para o ano de 2010, totalizam 1.450 unidades. Sendo possível identificar que apenas 5 das 18 cidades apresentam número superior a 100, sendo Araci, Monte Santo, Santaluz, Tucano e Valente, das quais a cidade que possui maior número é Tucano com 195, enquanto a de menor é Ichú com 28. Embora esse não seja um dado tão relevante, uma vez que o uso da telefonia móvel se ampliou consideravelmente, mas ainda é disponibilizado pela ANATEL.

A partir das pesquisas realizadas foi possível a identificação de 38 portais de notícias nas/das Cidades Pequenas, contatando-se que é recorrente a utilização dos portais, inclusive é perceptível a existência de 27 portais específicos da cidade sede e 11 que abrangem todo o 
Território do Sisal, constituindo-se como uma via de interação entre as cidades do território referido.

As emissoras licenciadas de Rádio e TV, considerando as categorias: Comunitária, FM e OM, contabilizam 20, das quais a comunitária tem predominância, o que se justifica pelo fato de essa ser uma categoria de mídia local, que prioriza a realidade de um povo, seus costumes e hábitos.

O Território do Sisal é atendido por cinco empresas de telefonia autorizada, sendo elas Claro S.A., Nextel Telecomunicações LTDA, Oi Móvel S.A., Telefônica Brasil S.A. e TIM Celular S.A. A partir da análise do mapa 01 pode-se inferir que nenhuma das cidades pequenas possuem as cinco empresas atuando, apenas a cidade de Conceição do Coité (que faz parte do Território do Sisal, mas para a pesquisa não foi considerada como cidade pequena). A empresa Claro S.A, abrange toda a extensão do território, com a exceção de Quijingue, Telefônica Brasil S.A. atende 14 cidades, TIM Celular S.A. 13, enquanto Nextel Telecomunicações LTDA e Oi Móvel S.A. somente quatro em ambas.

Apenas a cidade de Conceição do Coité é atendida pelas cinco empresas, enquanto há cidades que são atendidas somente por uma, como Candeal, Ichú, Lamarão e Quijingue. As cidades de Araci, Barrocas, Teofilândia e Tucano, possuem quatro empresas autorizadas, já Cansanção, Monte Santo, Nordestina, Retirolândia, Santaluz, Valente possuem três empresas, e Biritinga, Itiúba, Queimadas e São Domingos apenas duas.

Figura 01:

Empresas de telefonia autorizadas por município. Território do Sisal.2015

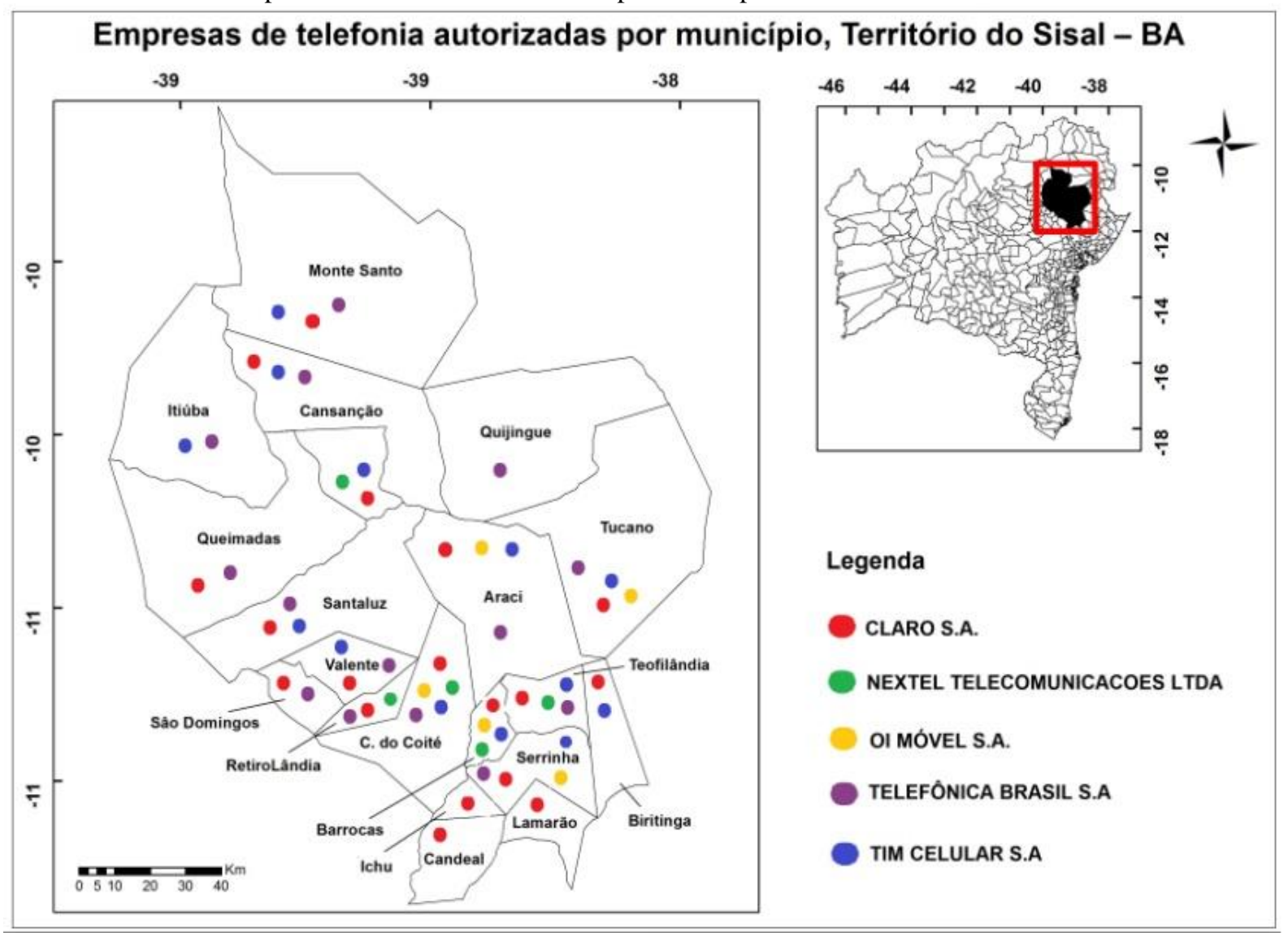

FONTE: ANATEL, 2015,

ELABORAÇÃO: MOTA, B.S.O. 2017

Com relação à posse de Microcomputador com acesso à internet, se destacam as Cidades Pequenas de Santaluz e Tucano com mais de 1.000, enquanto Candeal e Lamarão possuem menos de 100. Os valores para rádio e Telefonia Móvel constatados são bastante 
similares, nos quais, para ambos, as cidades pequenas de Araci, Santaluz e Tucano possuem mais de 4.000 residências com os serviços, enquanto Lamarão possui menos de 600. Quanto a Telefonia Fixa a Cidade Pequena de Araci apresenta a maior estatística com 874, em oposição a Lamarão que possui 110. Para Televisão Tucano, Santaluz e Araci respectivamente apresentam valores acima de 5.000, a medida que Candeal, Ichú e Lamarão possuem menos de 1.000. Constatando- se que o serviço mais utilizado no Território do Sisal é a Televisão, em seguida o rádio e Telefonia móvel com valores próximos, Microcomputador com acesso à internet e o menos utilizado, a Telefonia fixa.

Castells (2001) discute como o surgimento de uma comunicação eletrônica, mediada por múltiplos veículos interativos, impulsionados pela globalização, proporcionaram durante a década de 1990, grande disputa entre governos e empresas, devido ao ideário de poder, altos lucros e modernidade. No Brasil, a reestruturação das telecomunicações aconteceu na década de 1990 e no Território do Sisal isso também foi notado.

Mesmo no contexto atual, tal sistema de comunicação, é caracterizado pela seletividade e rotulação no mundo atual globalizado e capitalista, sendo responsável pelo desenvolvimento de um novo ambiente simbólico.

\section{CONSIDERAÇÕES FINAIS (ou Conclusão)}

O estudo realizado permitiu identificar que a reestruturação do setor das Telecomunicações se deu concomitantemente à restruturação da cadeia produtiva do sisal após uma crise, ambos na década de 1990, permitindo identificar a relação existente, e a importância do setor para a dinâmica territorial das Cidades Pequenas, que em geral é bastante singular quando se considera por exemplo, a base econômica concentrada na produção de sisal e artefatos derivados.

As Telecomunicações exercem importante interferência tanto para o município especificamente, quanto para a o território como um todo, interligando as pequenas cidades através dos diversos meios de telecomunicações, de modo que as mesmas possam interagir rapidamente, facilitando a efetivação de vínculos, mesmo que em algumas os serviços sejam limitados, catalisa a disseminação de informações, contatos, relações comerciais entre outras formas de articulações.

Portanto, a organização espacial das Cidades Pequenas é diretamente influenciada pelas Telecomunicações, que ao tempo em que promovem a relação positiva entre as mesmas, desempenham a seleção desigual do território através dos diferentes agentes que atuam em prol do acúmulo do capital, sendo comprovado a partir dos dados obtidos que demonstram variações exorbitantes.

\section{REFERÊNCIAS}

ANATEL, Dados de acessos. Disponível em: <http://www.anatel.gov.br/institucional/> Acesso em 10 de outubro de 2016.

BRASIL. Presidência da República. Casa Civil. Subchefia para Assuntos Jurídicos. Lei no 7.512, de junho de 2011. Aprova o Plano Geral de Metas para a Universalização do Serviço Telefônico Fixo Comutado Prestado no Regime Público - PGMU, e dá outras providências. Disponível em: <http://www.planalto.gov.br/ccivil_03/_ato20112014/2011/decreto/d7512.htm> Acesso em: 31 de mar. 2017.

CASTELLS, Manuel. A sociedade em rede, vol. 1. São Paulo: Paz e Terra, v. 1, 2001. 617p.

SANTOS, E.; NETO, A.; SILVA, O. De Região Sisaleira a Território do Sisal: desvelando nuances do processo de delimitação da diferenciação espacial no Semiárido Baiano. GeoTextos, v. 11, n. 2, 2015.

SANTOS, M. A natureza do espaço: Técnica e Tempo. Razão e Emoção. 4 ed. São Paulo: Editora da Universidade de São Paulo, 2006. 259 p. 